\title{
Increased peri-ductal collagen micro- organization may contribute to raised mammographic density
}

\author{
James C. McConnell', Oliver V. O'Connell ${ }^{2}$, Keith Brennan², Lisa Weiping ${ }^{2}$, Miles Howe ${ }^{3}$, Leena Joseph³,
} David Knight ${ }^{2}$, Ronan O'Cualain ${ }^{2}$, Yit Lim ${ }^{3}$, Angela Leek ${ }^{6}$, Rachael Waddington ${ }^{6}$, Jane Rogann ${ }^{6}$, Susan M. Astley ${ }^{4}$, Ashu Gandhi ${ }^{3}$, Cliona C. Kirwan ${ }^{5}$, Michael J. Sherratt ${ }^{1 *}$ and Charles H. Streuli ${ }^{2}$

\begin{abstract}
Background: High mammographic density is a therapeutically modifiable risk factor for breast cancer. Although mammographic density is correlated with the relative abundance of collagen-rich fibroglandular tissue, the causative mechanisms, associated structural remodelling and mechanical consequences remain poorly defined. In this study we have developed a new collaborative bedside-to-bench workflow to determine the relationship between mammographic density, collagen abundance and alignment, tissue stiffness and the expression of extracellular matrix organising proteins.
\end{abstract}

Methods: Mammographic density was assessed in 22 post-menopausal women (aged 54-66 y). A radiologist and a pathologist identified and excised regions of elevated non-cancerous X-ray density prior to laboratory characterization. Collagen abundance was determined by both Masson's trichrome and Picrosirius red staining (which enhances collagen birefringence when viewed under polarised light). The structural specificity of these collagen visualisation methods was determined by comparing the relative birefringence and ultrastructure (visualised by atomic force microscopy) of unaligned collagen I fibrils in reconstituted gels with the highly aligned collagen fibrils in rat tail tendon. Localised collagen fibril organisation and stiffness was also evaluated in tissue sections by atomic force microscopy/ spectroscopy and the abundance of key extracellular proteins was assessed using mass spectrometry.

Results: Mammographic density was positively correlated with the abundance of aligned periductal fibrils rather than with the abundance of amorphous collagen. Compared with matched tissue resected from the breasts of low mammographic density patients, the highly birefringent tissue in mammographically dense breasts was both significantly stiffer and characterised by large (>80 $\mu \mathrm{m}$ long) fibrillar collagen bundles. Subsequent proteomic analyses not only confirmed the absence of collagen fibrosis in high mammographic density tissue, but additionally identified the up-regulation of periostin and collagen XVI (regulators of collagen fibril structure and architecture) as potential mediators of localised mechanical stiffness.

Conclusions: These preliminary data suggest that remodelling, and hence stiffening, of the existing stromal collagen microarchitecture promotes high mammographic density within the breast. In turn, this aberrant mechanical environment may trigger neoplasia-associated mechanotransduction pathways within the epithelial cell population.

Keywords: Mammographic density, Collagen organisation, Tissue micro-stiffness, Atomic force microscopy, Breast cancer, Cancer risk

\footnotetext{
* Correspondence: michael.sherratt@manchester.ac.uk

${ }^{1}$ Centre for Tissue Injury \& Repair, Faculty of Medical and Human Sciences,

University of Manchester, Manchester, UK

Full list of author information is available at the end of the article
} 


\section{Background}

Although the causative mechanisms of most breast cancers remain poorly understood, epidemiological evidence indicates that women with radiopaque tissue occupying over $60 \%$ of the breast are three to six times more likely to develop cancer than those with predominantly radio-translucent tissue [1, 2]. As a consequence, the proportion of radio-dense breast tissue (commonly referred to as mammographic density (MD)) is an important breast cancer risk factor [3, 4]. Crucially, unlike most breast cancer risk factors, MD can be therapeutically modified. Prophylactic treatment of patients with high MD with tamoxifen or aromatase inhibitors can reduce MD and hence breast cancer risk, but unfortunately patient tolerance to such long-term endocrine therapy is low $[5,6]$. As yet the structural and compositional differences between dense and non-dense breasts, and the identity of potential therapeutic targets, remain poorly defined [7].

Since fat-rich adipose tissue is radiologically translucent, $\mathrm{MD}$ is determined primarily by the amount of fibroglandular material (comprising cell-rich epithelial and extracellular matrix (ECM)-rich stromal tissues) $[3,8,9]$. X-ray imaging combined with haematoxylin and eosin (H\&E) staining of breast tissue implicates stromal collagen fibrosis as a key factor in raised MD $[10,11]$. Such perturbations in ECM homeostasis may influence epithelial cell phenotype and tumour progression [12]. Moreover, changes in collagen organisation in the tumour microenvironment, may promote tumour initiation and progression [13]. Whilst the unmodified $\mathrm{H} \& \mathrm{E}$ staining protocol is well-suited to characterizing breast tissue architecture, it does not specifically identify collagen [14]. Previous studies have failed to delineate the causative mechanisms and biological consequences of increased MD because of: 1) the use of methodological approaches which are unsuited to detecting specific changes in micro-scale (i.e., cellular) ECM composition, organization and tissue stiffness and 2) inadequate control of sampling with regards to age, menopausal status and/or localized variations in breast density.

To overcome these shortcomings, and to define clear links between increased MD and altered breast biology, we have developed a new collaborative workflow for sampling localized regions of elevated density breast tissue from age-matched postmenopausal women. In this workflow, we have linked surgeon, radiologist, pathologist, tissue biobank, and laboratory scientist (Fig. 1). We use this workflow to test the hypothesis that increased MD in recently postmenopausal women is caused by the deposition of an ordered, and hence stiffened, fibrillar collagen matrix.

\section{Methods}

\section{Cohort}

Twenty-two women (54-66 years) were recruited from the Nightingale Centre breast-screening clinic. Although this Centre is one of the largest breast clinics in the UK, only about 30 suitable patients within this age range undergo surgery each year. Of these patients we were able to achieve a consent rate of 50-60\% during the duration of the study period. The local Research Ethics Committee approved the study, and all patients gave written informed consent. Women on hormone replacement therapy or who had neoadjuvant breast cancer treatment were not included in the study cohort.

\section{Ethics and consent statements}

These studies fall under the ethics approvals for the MCRC Biobank, which is licensed by the Human Tissue Authority (licence number 30004) and has been ethically approved as a research tissue bank by the South Manchester Research Ethics Committee (Reference 07/ H1003/161 + 5). Written informed consent was obtained at the time of tissue collection.

\section{Study workflow}

All of the study participants were characterised for breast cancer risk by oestrogen receptor (ER), human epidermal growth factor receptor 2 (HER-2) and breast cancer gene (BRCA) status - none of the individuals recruited were BRCA-positive. A clinical radiologist assessed digital mammograms from each patient, and identified the area of highest radiographic density. All studies were performed on tissue situated at least $4 \mathrm{~cm}$ distant from any neoplasia. There is clear evidence from assessments of adipokine expression, genetic changes, mechanical properties, and radiofrequency characteristics, that tissue distant from the tumour margin will not be subject to a field change and hence can be considered to be benign [15-18]. Following surgery, highlighted tissue areas $\left(5-10 \mathrm{~mm}^{3}\right)$ were sampled from the area of high radiographic density in the resected breast, by a clinical histopathologist.

The samples were prepared for histological analysis of tissue architecture, and amorphous and aligned fibrillar collagen, by H\&E, Masson's trichrome and Picrosirius red (PSR) staining, respectively. MD was quantified by image analysis (Volpara ${ }^{\circledR}$ breast density [19]), validated against visual estimation recorded on a visual analogue scale (VAS) by a single experienced assessor. In six individuals with low and six with high MD (Table 1) micromechanical analysis was performed on sections cut from frozen tissue samples. Subsequently, ultrastructural and proteomic analyses were carried out on six tissue samples ( $\mathrm{n}=3$ /group). Tissue samples were assessed by a histopathologist to confirm the absence of neoplasias. 


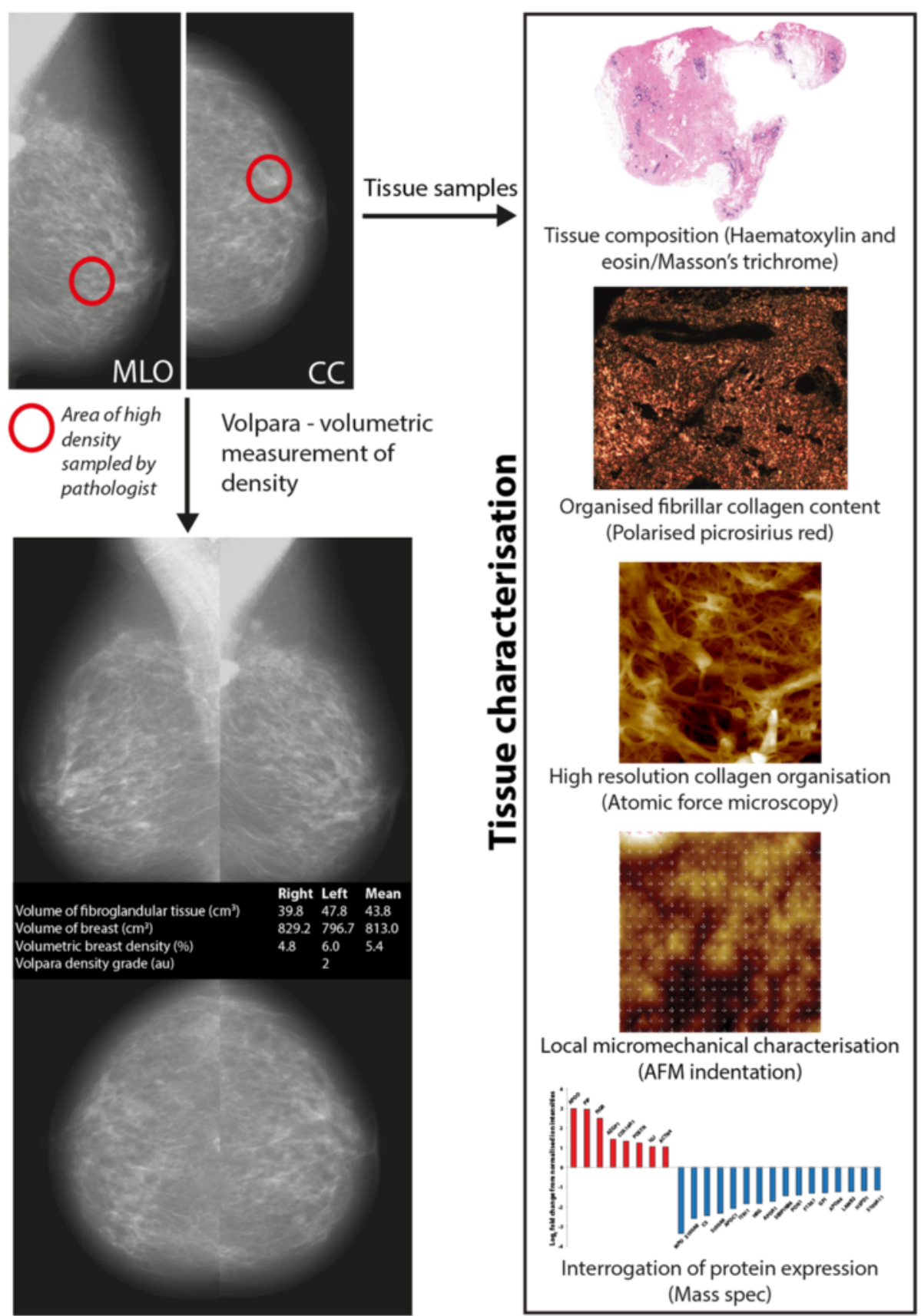

Fig. 1 A novel workflow for sampling radio-dense breast tissue. A radiologist identified regions of elevated radiographic density in digital mammograms which were then excised by a pathologist prior to histological characterization of collagen abundance and organization in all 22 patients. CC craniocaudal view, MLO mediolateral oblique view. Following stratification of patients into low and high mammographic density (MD) groups (by Volpara ${ }^{\oplus}$ score), in regions of the tissue at least $4 \mathrm{~cm}$ from any tumours the molecular, ultrastructural and micro-mechanical drivers of MD were characterized as individuals with low $(n=6)$ and high $(n=6)$ MD by atomic force microscopy (AFM). Three of each of the samples with low and high MD (low-MS, and high-MS) were also analysed by mass spectrometry (mass spec). AFM atomic force microscopy

\section{Mammographic density}

For each patient, mediolateral oblique (MLO) and craniocaudal (CC) digital mammograms were processed by Volpara $^{\circ}$ to compute the percentage of the breast volume occupied by dense tissue $[19,20]$. They were also assessed by an experienced radiologist who recorded the percentage of the breast area occupied by dense tissue on a VAS.

\section{Tissue histology}

H\&E and Masson's trichrome staining were used to assess cellularity, stromal and fat content and the 
abundance of amorphous collagen [21, 22]. Tissue samples were bisected, one half was fixed overnight in $4 \%$ paraformaldehyde in PBS before processing to wax with an ASP6025 automated tissue processor (Leica, Newcastle, UK). Sections (3 $\mu \mathrm{m}$ thick) were adhered to positively charged slides, before dewaxing and methanol processing prior to staining. Following batch staining with the histology stains H\&E and Masson's trichrome, mounted sections were imaged sequentially using an SCN400 digital slide scanner (Leica, Newcastle, UK), with a Leica NA Plan Apo $\times 20 / 0.75$ objective. Slides were only scanned in areas where specimen tissue was present. Resulting images $(0.46 \mu \mathrm{m} /$ pixel resolution) were saved in the MIRAX format. Image analysis was performed with custom-written rule sets for the Tissue Studio 3 software package (Definiens, Munich, Germany) [23]. More specifically, images were thresholded using the hue, saturation and brightness colour space with epithelial regions identified as the areas of lowest brightness and hue, adipose regions as areas of highest brightness and hue and stromal regions as intermediate values.

\section{Fibrillar collagen abundance and organisation}

As ECM organisation, and not just abundance, plays a key role in determining the mechanical properties of tissues [24], we additionally stained breast tissue samples with PSR ( $1 \mathrm{~h}$ incubation with $0.1 \%$ sirius red F3BA in saturated aqueous picric acid at $\mathrm{pH} 2$ followed by clearing in $0.1 \%$ HAc, dehydration and mounting in DPX) [25]. When visualised under cross-polarised light, the resultant collagen-associated birefringence can be semiquantitatively assessed against total tissue area [26, 27]. To clarify whether this PSR enhanced birefringence was induced by collagen fibrils alone [28], or only by assembled collagen fibrils aligned into fibres [25], we assessed the ability of PSR/polarised light microscopy to visualise aligned collagen I fibrils in young Wistar rat tail tendon, and in non-aligned fibrils reconstituted in vitro from bovine collagen I (Thermo Fisher Scientific Ltd., Loughborough, UK). Collagen fibril gels were formed at $37{ }^{\circ} \mathrm{C}$ in a hydrated atmosphere, with a gelation time of approximately 30 minutes [29]. Additional quantitative analyses of collagen orientation (coherency) were conducted on PSR stained images using a well-established methodology [105].

\section{Ultrastructure}

We have previously shown that AFM can readily image nano-scale structural detail in unstained tissue cryosections [30]. We applied this technique to characterise the effects of MD on fibrillar collagen organisation in peri-ductal tissues, and to compare the ultrastructural architecture of collagen fibrils in rat tail tendon and reconstituted gels. The other halves of the bisected breast tissue samples, along with the rat tail tendon

Table 1 Clinical and mammographic assessment of the patient cohort

\begin{tabular}{|c|c|c|c|c|c|c|c|c|c|c|c|c|c|}
\hline $\begin{array}{r}\begin{array}{r}\text { Selected } \\
\text { Mechanics }\end{array} \\
\end{array}$ & $\begin{array}{l}\text { samples } \\
\text { Proteomics }\end{array}$ & $\begin{array}{c}\text { Patient } \\
\text { ID }\end{array}$ & \begin{tabular}{|c|}
$\begin{array}{c}\text { MD by } \\
\text { volume } \\
\text { (Volpara) }\end{array}$ \\
\end{tabular} & $\begin{array}{c}\text { MD by } \\
\text { area } \\
\text { (VAS) } \\
\end{array}$ & $\begin{array}{c}\text { Breast } \\
\text { Histology }\end{array}$ & \begin{tabular}{|c}
$\begin{array}{c}\text { Tumour } \\
\text { Size } \\
(\mathrm{mm})\end{array}$ \\
\end{tabular} & $\begin{array}{c}\text { Tumour } \\
\text { Grade }\end{array}$ & $\begin{array}{c}\text { ER } \\
\text { Status }\end{array}$ & $\begin{array}{l}\text { HER-2 } \\
\text { status }\end{array}$ & Age (y) & $\begin{array}{l}\text { Height } \\
\text { (m) }\end{array}$ & $\begin{array}{c}\text { Weight } \\
\text { (kg) }\end{array}$ & BMI \\
\hline & 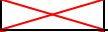 & 2 & 25 & 69.3 & RRMx & - & - & - & - & 57 & 1.5 & 51 & 22.7 \\
\hline$>$ & 3 & 4 & 16 & 63.6 & IDC & 80 & 3 & neg & pos & 60 & 1.73 & 114 & 38.1 \\
\hline & $\sum$ & 15 & 16 & 59.9 & IDC & 18 & 1 & pos & neg & 57 & 1.62 & 57 & 21.7 \\
\hline & & 12 & 14 & 56.8 & ILC/IDC & 16 & 2 & pos & neg & 63 & 1.75 & 69 & 22.5 \\
\hline & & 13 & 12 & 37 & IDC & 60 & 3 & neg & neg & 59 & 1.65 & 60 & 22.0 \\
\hline & & 9 & 12 & 43.9 & DCIS & 80 & 3 & pos & - & 58 & 1.55 & 56 & 23.3 \\
\hline & & 5 & 11 & 49.3 & IDC & 17 & 3 & neg & neg & 62 & 1.52 & 57 & 24.7 \\
\hline & & 17 & 9 & 48.8 & IDC & 24 & 3 & neg & pos & 59 & 1.72 & 67 & 22.6 \\
\hline & & 3 & 9 & 45.5 & IDC & - & 1 & pos & neg & 58 & 1.62 & 64 & 24.4 \\
\hline & & 6 & 9 & 52.6 & IDC & 9 & 2 & pos & pos & 62 & 1.60 & 57 & 22.3 \\
\hline & & 14 & 9 & 41.9 & IDC & 36 & 3 & neg & neg & 55 & 1.61 & 58 & 22.4 \\
\hline & & 7 & 8 & 40.4 & IDC & 38 & 3 & pos & pos & 59 & 1.73 & 74 & 24.7 \\
\hline & & 21 & 8 & 47.4 & ILC & 30 & 2 & pos & neg & 64 & 1.55 & 74 & 30.8 \\
\hline & & 1 & 7 & 16.1 & RRMx & - & - & - & - & 58 & 1.65 & 61 & 22.4 \\
\hline & & 18 & 6 & 36.6 & IDC & 30 & 3 & pos & neg & 66 & 1.71 & 88 & 30.1 \\
\hline & 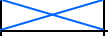 & 10 & 6 & 27.3 & RRMx & - & - & - & - & 59 & 1.69 & 68 & 23.8 \\
\hline & & 20 & 6 & 31.1 & IDC & 24 & 2 & pos & neg & 58 & 1.57 & 62 & 25.2 \\
\hline & & 8 & 5 & 38.1 & IDC & 13 & 2 & pos & neg & 54 & 1.57 & 67 & 27.2 \\
\hline & & 16 & 5 & 30 & IDC & 39 & 3 & neg & pos & 58 & 1.64 & 63 & 23.4 \\
\hline 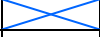 & $2<$ & 11 & 4 & 18.5 & RRMx & - & - & - & - & 58 & 1.64 & 100 & 37.2 \\
\hline & & 19 & 4 & 34.8 & ILC & 28 & 2 & pos & pos & 63 & 1.55 & 115 & 47.9 \\
\hline 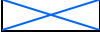 & & 22 & 3 & 10.8 & IDC & 19 & 3 & pos & pos & 66 & 1.52 & 93 & 40.3 \\
\hline
\end{tabular}

Disease status of patients assessed histologically. Also indicated are the age, height, and weight of each individual as well as the high (red) and low (blue) individuals selected for both micromechanical and proteomic analyses (crossed boxes). BMI body mass index, DCIS ductal carcinoma in situ, HER-2 human epidermal growth factor receptor, IDC invasive ductal carcinoma, ILC invasive lobular carcinoma, neg negative, $E R$ oestrogen receptor, pos positive, $R R M x$ risk-reducing mastectomy, VAS visual analogue score 
and reconstituted collagen fibrils were embedded in optimal cutting temperature cryo-sectioning media and snap frozen into a $2.5-\mathrm{cm}$ mould with liquid nitrogen cooled isopentane [30]. Frozen sections were then cut to a nominal thickness of $5 \mu \mathrm{m}$ in a cryostat microtome at $-20{ }^{\circ} \mathrm{C}$, air dried, washed in distilled $\mathrm{H} 2 \mathrm{O}$ and stored at $4{ }^{\circ} \mathrm{C}$. Subsequently these cryosections were imaged by a Bioscope Catalyst utilising Bruker's ScanAsyst PeakForce mode (Bruker, Coventry, UK), a Bruker Scanasyst Air triangular silicon nitride cantilever (nominal spring constant of $0.2 \mathrm{~N} / \mathrm{m}$ and a pyramidal tip of nominal radius of $2 \mathrm{~nm}$ ). Height and amplitude images were captured at two scan sizes. For smaller scan areas, $10 \times 10 \mu \mathrm{m}$ was assessed at a scan frequency of 0.25 $\mathrm{Hz}$ and a sampling frequency of $1024 \times 1024$ (for a lateral spacing of $9.76 \mathrm{~nm}$ ), whereas for large areas $150 \times 150 \mu \mathrm{m}$ was assessed at a scan frequency of $0.01 \mathrm{~Hz}$ and a sampling frequency $4992 \times 4992$ (for a lateral spacing of $30.05 \mathrm{~nm})$.

\section{Control collagen samples}

Rat tail tendon was extracted from intact tail following sacrifice of 12-month-old Wistar rats. Whole collagen fibre bundles were removed from the tail, fixed overnight in $4 \%$ paraformaldehyde in PBS before processing to wax (as before). Sections ( $3 \mu \mathrm{m}$ thick) were adhered to positively charged slides and dewaxed before staining or AFM analysis. Re-constituted collagen gels were made from Bovine Collagen I (Gibco, Warrington, UK) by treating collagen at $5 \mathrm{mg} / \mathrm{mL}$ with $1 \mathrm{~N} \mathrm{NaOH}$ on ice to produce a total volume of 2 ul. This liquid suspension was placed onto a charged slide where it was allowed to dry down overnight and rinsed with distilled water before being assessed for collagen fibril abundance and organisation by both polarised light microscopy of PSR stained sections and AFM..

\section{Tissue micro-mechanics}

Micro-indentation of rat tail tendon reconstituted collagen fibrils and peri-ductal breast tissue (from six patients with low MD and six with high MD) was carried out using $5 \mu \mathrm{m}$ thick cryo-sections and a Bioscope Catalyst AFM (Bruker, Coventry, UK) mounted onto an Eclipse T1 inverted optical microscope (Nikon, Kingston, UK) fitted with a spherically tipped cantilever (nominal radius and spring constant of $1 \mu \mathrm{m}$ and $3 \mathrm{Nm}^{-1}$ respectively: Windsor Scientific Ltd., Slough, UK,) running Nanoscope Software v 8.15 (Bruker, Coventry, UK). The local reduced modulus was determined for each of 400 points in a $25 \times 25 \mu \mathrm{m}$ region, indented at a frequency of $1 \mathrm{~Hz}$ with lateral spacing of $1.25 \mu \mathrm{m}$. The extend curve was used in conjunction with a contact-point-based model to calculate the reduced modulus for each indentation [31]. For each biological sample, three $25-\mu \mathrm{m}^{2}$ regions, and hence 1,200 force curves, were collected. Post hoc analyses of force curves were performed using Nanoscope Analysis v 1.40 (Bruker, Coventry, UK), whereby a baseline correction was applied to each curve before a force fit was applied using the Herzian (spherical) model and a maximum force fit of $70 \%$. Once all 400 force curves had been generated, quality control was applied, whereby any force values falling more than two standard deviations away from the mean value were discarded in order to account for failed indents. In general fewer than $10 \%$ of force curves were excluded. (data not shown). Note that in the same breast samples, there was no significant difference between the reduced modulus of 5-uM-thick sections $(440 \mathrm{kPa} \pm 12)$ and 20 -uM-thick sections (450 $\mathrm{kPa} \pm 17, \mathrm{n}=1,200, p>0.0001)$.

\section{Proteomics}

Frozen tissue $(20 \mathrm{mg}$ ) from three individuals with low and three with high overall $\mathrm{MD}$ was used to assess protein content by mass spectrometry conducted in the Faculty of Life Sciences Biological Mass Spectrometry Facility (Bio-MS). Tissues were disrupted using a Fisher 120 sonic dismembrator (Thermo Fisher, Cramlington, $\mathrm{UK}$ ) and resuspended in $8 \mathrm{M}$ urea $0.1 \mathrm{M}$ Tris $\mathrm{HCl}$ pH8.5 [32]. The solubilised protein level was quantified using a Direct Detect system (Millipore, Billerica, MA, USA) and 25 ug were taken for subsequent digestion. Proteins were then digested using a variant of the filteraided sample preparation (FASP) method [33] whereby proteins were solubilised in urea instead of SDS. In brief, proteins were reduced with dithiothreitol and alkylated with iodoacetamide in the presence of $8 \mathrm{M}$ urea in a Micron $30 \mathrm{kDa}$ centrifugal unit followed by predigestion with LysC in $6 \mathrm{M}$ urea before digestion with trypsin in $1.5 \mathrm{M}$ urea. The resultant peptides were desalted into $0.1 \%$ formic acid in $5 \%$ acetonitrile using Poros R3 reversed phase chromatographic media (Life technologies, Carlsbad, CA, USA) housed in 0.20-um polyvinylidene fluoride (PVDF) filter 96-well plates (Corning, New York, NY, USA). Liquid chromatographymass spectrometry (LC-MS/MS) was performed using an Orbitrap Elite ${ }^{\mathrm{Tm}}$ Hybrid Ion Trap-Orbitrap Mass Spectrometer coupled with a nano U3000 chromatography system (both Thermo Fisher, as before). The data produced was quantified using Progenesis LC-MS (Non-Linear Dynamics, Newcastle, UK) and identified using Mascot (Matrix Science, London, UK). Proteins identified by mass spectrometry (MS) were allocated to categories according to their Gene Ontology (GO) cellular compartment annotation, and enrichment of GO terms was assessed using enrichment analysis in Cytoscape (NRNB, Bethesda, Maryland, USA) [34]. 

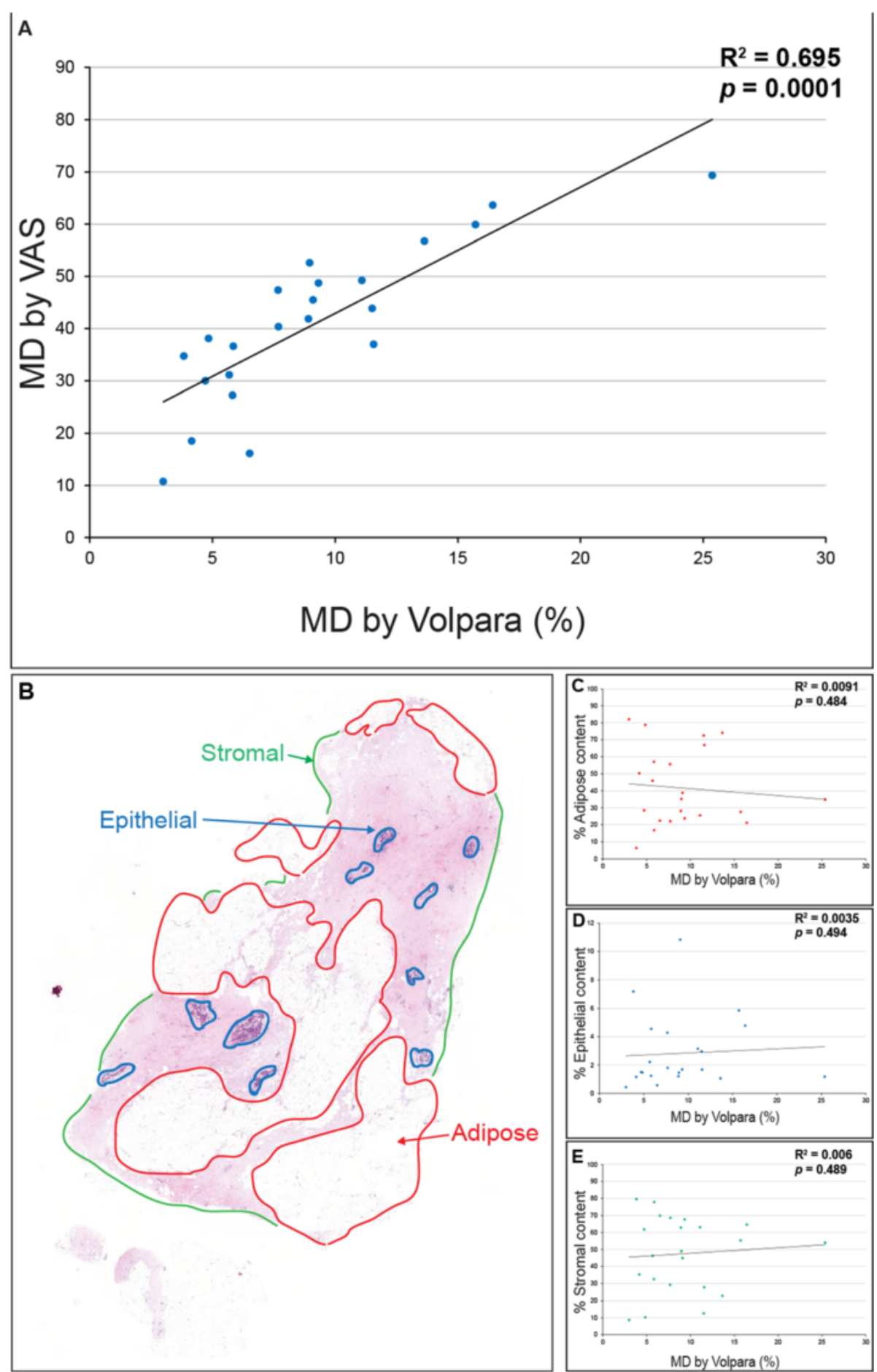

Fig. 2 Assessment of mammographic density and tissue architecture. $\mathbf{a}$, b There was a significant correlation between two common methods of assessing mammographic density (MD), visual analogue scale (VAS) and Volpara ${ }^{\circledast}$ (a). b H\&E-stained paraffin section of resected breast tissue (low MD). Adipose, epithelial and stromal tissues are highlighted in red, blue and green respectively. c-e Tissue architecture (adipose, epithelial and stromal content) was not significantly correlated with MD

\section{Statistical analyses}

The non-parametric Mann-Whitney $U$ test was applied to determine significance (Graphpad Instat La Jolla, CA,
USA). Values are reported as mean \pm SD. Analysis of AFM data was conducted using SPSS 20 (SPSS, Chicago, IL, USA). Normal distribution was confirmed by $q-q$ 
plot. One-way analysis of variance (ANOVA) was used to compare means. For all analyses, a value $p<0.05$ was considered statistically significant.

\section{Results and discussion}

\section{Patient cohort and assessment of MD}

A cohort of 22 postmenopausal women $(59.7 \pm 3.2$ years $)$ was recruited (Table 1). Compared with previous studies, this cohort was well-defined with regards to age and menopausal status $[10,11]$. In 18 patients, cancers were diagnosed by a combination of clinical and radiological investigation (bilateral mammography and ultrasound scanning). Histological confirmation of malignancy in these individuals was obtained from a clinically derived image-guided core biopsy. No patients had metastases or cancer cell involvement with the breast skin or chest wall. For this study, we only analysed biopsies that were confirmed to be neoplasia-free by a clinical histopathologist following examination of H\&E and Masson's trichrome stained sections. The samples studied were on tissue situated at least $4 \mathrm{~cm}$ distant from any neoplasia. Four women did not have a diagnosis of breast malignancy, and were undergoing bilateral risk-reducing mastectomy.

An experienced consultant breast radiologist assessed MD. Density ranged from 11-69 \% using a VAS, while percent breast density measured by automated volumetric breast density software (Volpara ${ }^{\circ}$ ) varied between $3 \%$ and $25 \%$ (Table 1). There was a significant correlation between these two methods of measuring $\mathrm{MD}\left(r^{2}=0.70\right.$, $p<0.001$ ) (Fig. 2a). Volumetric approaches for measuring breast density (as implemented by Volpara ${ }^{\circ}$ ) have been extensively validated against objective reference standard measurements obtained from magnetic resonance imaging (MRI) [35, 36] and the potential benefits of using multiple measures of MD have previously been highlighted [4]. In our study, the VAS and Volpara approaches identified the same individuals with high MD (Table 1: patients 2, 4 and 15). Moreover, there was no significant difference between MD (as measured by either technique) in women diagnosed with a tumour and those who were tumour-free, or significant correlation between MD and tumour size (data not shown). In addition, MD was also unrelated to tumour size (MD by Volpara $^{\circ}, r^{2}=0.150, p=0.57$; MD by VAS, $r^{2}=0.018$, $p=0.95$, data not shown).

Together these studies identified regions of normal, non-neoplastic breast tissue of varying $\mathrm{MD}$, which were used for further analysis. This element of the study design is key as it demonstrates that we are assessing normal tissue rather than tissue remodelled by tumour cells. Moreover, the expression of adipokines and fatty acids is reported to differ significantly in the peri-tumour area compared to distant tissue [15], indicating that sampling regions $4 \mathrm{~cm}$ distant from the tumour will ameliorate any effect of the tumour on the normal tissue sampled. Also, genetic changes occurring distant from HER2amplified breast cancers result from tumour cell contamination rather than a field change [17]. Body mass index (BMI), a strong indicator of overall adiposity and therefore breast fat content, was not significantly correlated with MD in our cohort, suggesting that adipose content is not a mediator of MD in these individuals (Table 1).

\section{MD correlates with collagen birefringence}

To assess the potential role of stromal and parenchymal remodelling in driving increased MD, we quantified epithelial, adipose and stromal content in H\&Estained sections using automated intensity segmentation (Fig. 2b-e). Although the proportion of these tissues varied markedly between individuals (epithelial: $<1 \%$ to $>10 \%$, adipose: $<10 \%$ to $>80 \%$, stromal: $<20 \%$ to $>80 \%$ ) there was no evidence of a relationship between tissue micro-architecture and MD $\left(r^{2}=0.0004\right.$ to $0.0053, p=0.484$ to 0.494 ). These observations contrast with the findings of previous studies, which reported a positive correlation between $\mathrm{MD}$ and fibroglandular (epithelial and stromal) content in the breasts of pre- and postmenopausal women aged 20-83 [9] and 40-82 years [8], respectively. By controlling for age and menopausal status, our study suggests that in the absence of largerscale remodelling events, loss of stromal ECM homeostasis may drive changes in MD.

Previous studies have identified stromal collagen deposition, as quantified by Masson's trichrome [37] or $\mathrm{H} \& \mathrm{E}$ staining [10] as a mediator of MD. However, in the present cohort (Fig. 3a, b), we could find no correlation between MD and collagen content as determined by Masson's trichrome $\left(r^{2}=0.0053\right)$ (Fig. 3c). This disparity may again be due to the contrasting age and menopausal status of the patients in the studies. In contrast to the narrow age range (12 years) in our cohort, others have drawn their tissue samples from individuals aged 15-90 years [37]. Moreover, in another study using individuals of a 54-75-year age range, collagen abundance was assessed using a semiquantitate scoring technique on tissue sections stained with non-specific H\&E [10]. It is important that this architecture may not be maintained in regions of lower local radiographic density.

Although Masson's trichrome is thought to specifically stain amorphous collagen, it is generally accepted that PSR-enhanced birefringence in tissue sections is specific for fibrillar collagens only [22, 25]. Here, we identified a significant positive correlation between $\mathrm{MD}$ and localized, PSR-enhanced, collagen birefringence in periductal stroma (i.e., within $20 \mu \mathrm{m}$ of the ducts) (Fig. 3d and D: $\left.r^{2}=0.8658, p<0.0001\right)$, but not in perilobular or 


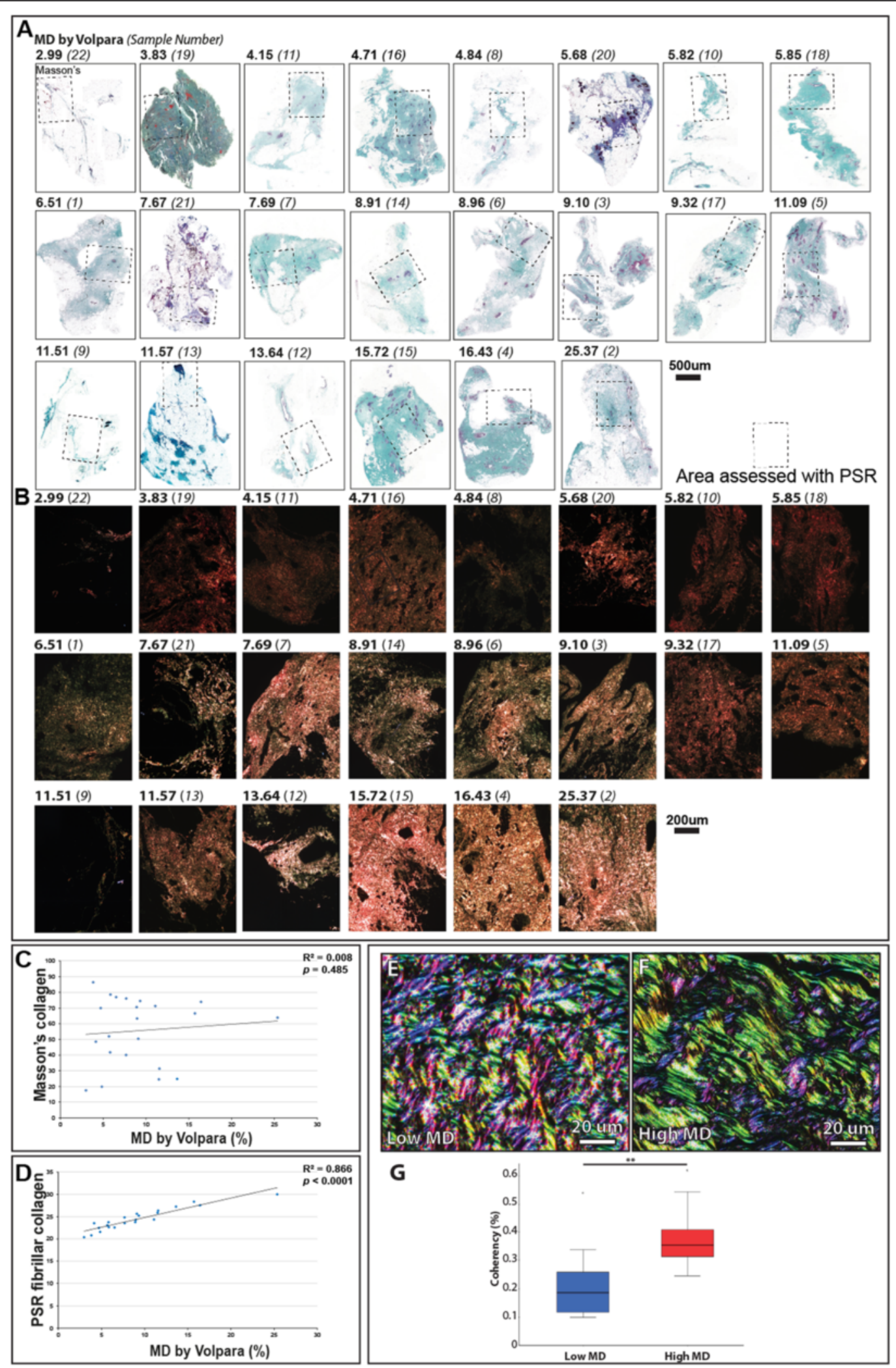

Fig. 3 (See legend on next page.) 
(See figure on previous page.)

Fig. 3 Relationship between mammographic density and amorphous and fibrillar collagen contents. a Masson's trichrome staining (amorphous collagen: blue/green, epithelial tissue: blue/black). Bold numbers denote Volpara score ${ }^{\oplus}$, anonymous patient identifiers are reported in parentheses. b, Serial paraffin sections stained with Picrosirius red (PSR) and visualised by polarised light microscopy. Note that the boxed regions (a) correspond to the areas corresponding to the enlarged PSR regions in $\mathbf{b}$. For each patient, three regions of the tissue shown in $\mathbf{a}$ were analysed in more detail by PSR staining and by Masson's trichrome staining. However for clarity, only one region is shown in a and $\mathbf{b}$. c Amorphous collagen content as visualized by Masson's trichrome staining was not correlated with mammographic density (MD). Note that for the quantitative data provided (c and $\mathbf{d}$ ), we analysed (as above) three regions of tissue for each sample, though for clarity only one region is shown in $\mathbf{a}$. $\mathbf{d}$ Fibrillar collagen content was significantly correlated with MD. e, f Polarised light microscopy of PSR-stained sections assessed using OrientationJ: e low MD, f high MD. Colour is indicative of fibre alignment. $\mathbf{g}$ Coherency of organised fibrillar collagen was significantly increased in high MD (0.38 \% \pm 0.11$)$ compared to low $\operatorname{MD}(0.21 \% \pm 0.11, p<0.001, \mathrm{n}=18)$

distal stroma (data not shown, perilobular: $r^{2}=0.1006$, $p=0.33$; distal stroma: $r^{2}=0.2381, p=0.14$ ). Together, these results suggest that the extent of patient MD in non-neoplastic tissue correlates with the amount of collagen birefringence revealed by PSR staining.

\section{Collagen birefringence correlates with fibril alignment} In common with many ECM structural proteins, fibrillar collagens (in particular collagens I and III) function as supra-molecular assemblies where monomers form fibrils, which in turn form fibres [13]. To characterize the effects of collagen organization on PSR-enhanced birefringence, we stained and visualized both collagen gels and rat-tail tendon cryosections. Despite being composed entirely of collagen I, PSR-stained collagen gels exhibited minimal birefringence under polarised light (Fig. 4a). In contrast, PSR-stained rat-tail tendon collagen was highly birefringent (Fig. $4 \mathrm{~b}$ ). Given the similarities in composition between the two systems, we reasoned that PSR-enhanced birefringence is critically dependent on either macro-molecular assembly of collagen monomers into fibrils, or supra-molecular assembly of fibrils into fibres. As the spatial resolution of conventional optical microscopy is insufficient to visualize individual collagen fibrils, we imaged collagen gel and tendon collagen cryosections by AFM [30]. Rather than containing amorphous collagen, both gel and tendon were composed of collagen fibrils (readily identified by their characteristic gap/overlap banding pattern) with similar periodicities of approximately $66 \mathrm{~nm}$ (inset in Fig. 4c and $\mathrm{d}$ and panel e). However, whilst the birefringent-negative fibrils in the gel were both heterogeneous in diameter and non-aligned, the birefringentpositive tendon fibrils were homogeneous in diameter and highly aligned (Fig. 4f). These results suggest that the PSR-enhanced collagen birefringence arises from fibril organisation with regards to its diameter and/or alignment, rather than its abundance.

We further explored this potential relationship by directly measuring the coherence (alignment) of birefringent collagen within peri-ductal regions in tissue sections taken from six patients with low and six with high MD (Fig. 3e, f) [105]. Collagen coherency was significantly higher in patients with high MD (Fig. 3g, Additional file 1: Figure S1). These results fit with previously published observations of tumour-associated collagen signatures in breast tumours, which suggest that ECM organisation is altered at the tumour-stroma boundary in more malignant tumours [100].

\section{Peri-ductal tissue contains large-diameter, stiff collagen fibres}

Having identified localized PSR-enhanced birefringence as the key marker for raised MD, we used AFM imaging and force spectroscopy to determine if it correlated with collagen fibril reorganization and local micro-stiffness. Peri-ductal collagen fibrils in breast derived from patients with high, but not low, MD were organized into aligned fibrous bundles (Fig. 5a, b). The bundles were evident in tissue samples from each of the patients with high MD and were remarkably homogenous in morphology (approximately $100-\mu \mathrm{m}$-long and $10-\mu \mathrm{m}$-wide; Fig. 5bi). They were connected to surrounding material by a network of smaller-diameter fibrils/fibres (Fig. 5bii). However, few comparable bundles were present in the peri-ductal tissue of individuals with low MD (Fig. 5ai). Tissue from these individuals was characterised by the presence of loose collagen aggregates (Fig. 5aii). These findings are consistent with studies suggesting that collagen fibrils are best resolved dehydrated, with rehydration performed when nano-mechanical measurements are required $[39,40]$.

Fibrillar collagens are important mediators of tissue tensile strength and stiffness, while changes in tissue mechanical properties are associated with cancer initiation and invasion [41-44]. We therefore assessed the functional consequences of peri-ductal collagen remodelling in six patients with high and six with low MD using localized AFM indentation of tissue cryosections (Fig. 5c-f). Mean reduced modulus (and hence localized tissue stiffness) varied between $100 \mathrm{kPa}$ and $820 \mathrm{kPa}$ (median $247 \mathrm{kPa}$ ) in patients with low $\mathrm{MD}$, compared with $200 \mathrm{kPa}$ to $1380 \mathrm{kPa}$ (median $611 \mathrm{kPa}$ ) in patients with high MD (Fig. 5e). These values are in agreement 

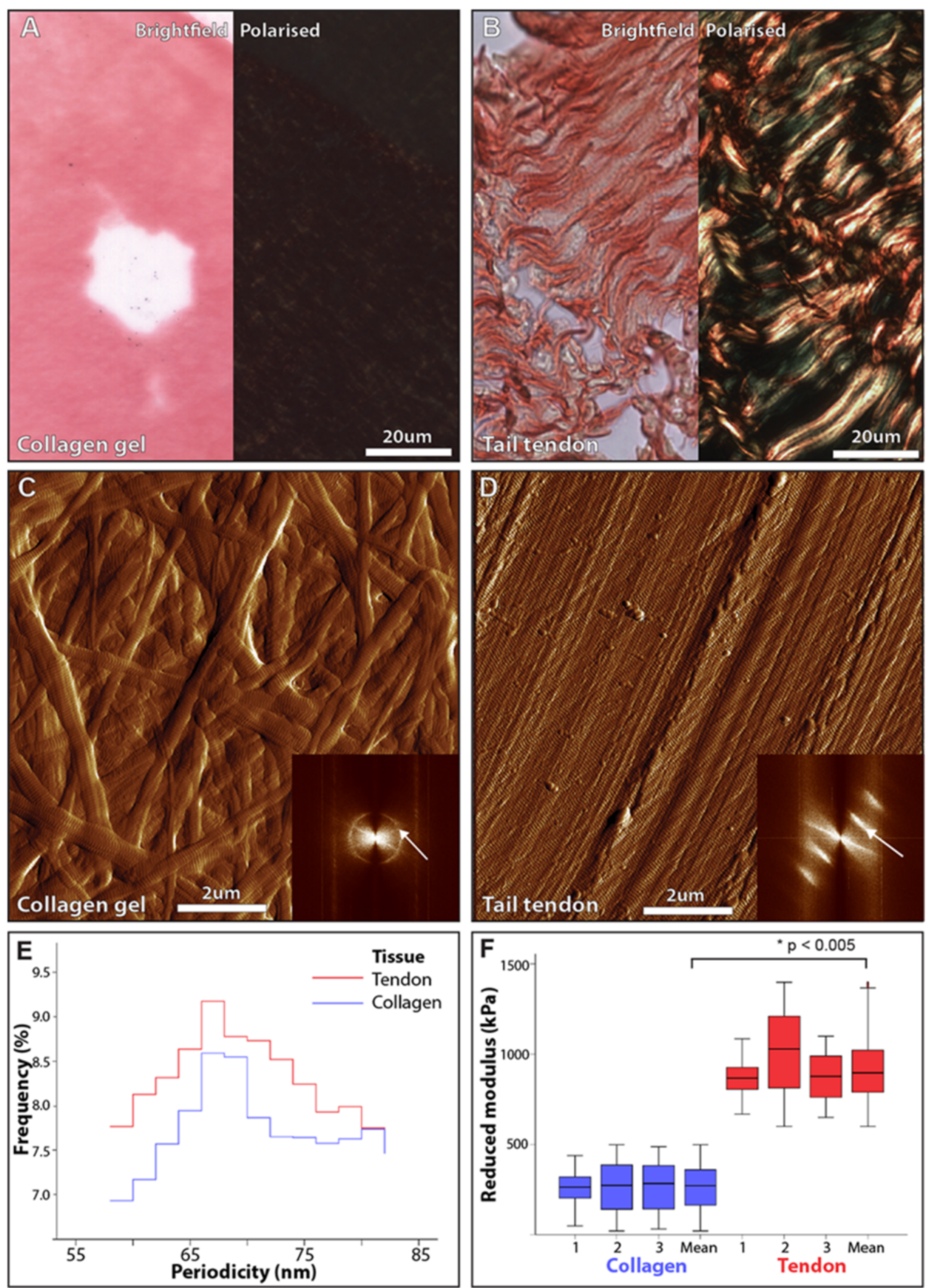

Fig. 4 (See legend on next page.) 
(See figure on previous page.)

Fig. 4 Picrosirius red-enhanced collagen birefringence in non-aligned collagen gels and aligned tendon collagen. $\mathbf{a}$, $\mathbf{b}$ Bright field (left) and polarised light microscopy (right) of PSR-stained cryosections cut from reconstituted collagen gels (a) and rat tail tendon (b). c, d Atomic force microscopy (AFM) height maps of collagen gels (c) and tendon (d). Collagen alignment and periodicity (white arrows) can be readily determined from fast fourier transform (FFT) of AFM amplitude images. Inset position of the fast fourier transform (FFT) signals corresponding to collagen periodicity (diffuse circles for the gel and discrete lines for the tendon) are indicated by arrows. e AFM-derived collagen periodicity. $\mathbf{f}$ Micro-mechanical stiffness (modulus (MPa)) of in vitro (gel) $(255 \mathrm{kPa} \pm 0.91)$ and in vivo (tendon) assembled collagen $(869 \mathrm{kPa} \pm 0.90, p<0.005)$

with recent work showing that when indented at lower loading rate, tissues with a high collagen fibre content have a reduced modulus in the range of hundreds of kilopascals [45]. In this analysis we utilised 5 - $\mu$ m-thick cryosections. Although these are relatively thin sections, it is widely accepted that if the indentation depth is smaller than $10 \%$ of the sample thickness, the effect of the substrate can be ignored [46]. In this study the indentation depth was $20 \mathrm{~nm}$ or less (as is required by PeakForce QNM: $[90,91]$ and we observed no statistical difference in reduced modulus between 5 - $\mu$ m-thick and $20-\mu$ m-thick sections (data not shown). The absolute modulus values that we report are however, considerably higher than those reported for fresh breast tissue [92, 93]. These disparities may be attributable to many factors including sample preparation (freezing and dehydration), probe characteristics (we use a large diameter tip, which is unlikely to puncture soft tissue [94] and the depth and location of the indentation (our cryo-section technique allows us to measure localised mechanical changes within the peri-ductal region).

Crucially however, whilst it is well-established that absolute values for indentation moduli are strongly influenced by the specific experimental conditions (even for the same tissues [95-97], our AFM system measures relative modulus values which are: 1) comparable with previous studies on the micro-mechanics of tendon [98] and skin [99] and 2) consistently and significantly higher in peri-ductal breast tissue of high MD. The cause of this peri-ductal stiffening may be due to the influence of differential crosslink formation between the two groups as a factor in local breast tissue stiffness, however, previous studies both in vitro (collagen scaffold formation) and in vivo (tendon stiffness) have shown that collagen fibril structure and organisation mediates the mechanical properties of materials $[47,48]$. Collectively, these results suggest that the increased stiffness of breasts of high $\mathrm{MD}$ is associated with remodelling of collagen fibrils into large-diameter peri-ductal stiff fibres, rather than the fibrotic deposition of additional collagen.

\section{High MD is associated with an increased abundance of collagen-organising proteins}

To identify potential causative mechanisms of raised $\mathrm{MD}$, we used mass spectrometry to characterise the proteomes of resected breast tissue from the patients with low and high MD ( $n=3$ /group). Proteomic analysis of ECM has been done in a few other tissues [106]. Moreover, an extensive set of ECM proteins has been revealed within rat mammary gland preparations [101, 102], and in tumours arising from MDA-MB-231 cell lines [103]. We have identified a significant number of similar ECM proteins within the human breast (Additional file 2: Table S1), and compared the proteomes of breast tissues isolated from different human samples with either low or high MD (Fig. 6, Additional file 3: Table S2). Eight proteins with raised abundance were present in tissues from patients with high MD, and a further sixteen proteins were less abundant. Although the analysis identified proteins that are markers of breast and other cancers, there was no proteomic evidence of a relationship between $\mathrm{MD}$ and collagen fibrosis.

Neo-collagen fibrillogenesis is associated with expression of proteins such as the collagen I and III alpha chains, collagen processing enzymes BMP-1/tolloid Cproteinases and ADMATS N-proteinases, and regulators of fibrillogenesis including collagen $\mathrm{V}$ and $\mathrm{XI}$, integrins $\alpha 5 \beta 1$ and $\alpha 2 \beta 1$, tenascin-X, thrombospondin 2 , cartilage oligomeric matrix protein, matrilins, perlecan and the small leucine-rich proteoglycans [49]. Instead, in tissue derived from patients with high MD in our study, mass spectrometry revealed increased levels of proteins that control collagen fibril interactions, diameter and crosslinking, including collagen XVI and periostin (1.3-fold and 1.2-fold increase, respectively) [50-52]. Collagen XVI and periostin have previously been detected in breast ECM, but this is the first time that their levels have been found altered in high vs low human MD breast tissue $[101,103]$. In addition there was a decreased abundance of the ECM protease inhibitors Serpin B6 and coagulation factor XIII A [53, 54].

Collagen XVI is a FACIT collagen that interacts with cells, and other ECM components including elastic-fibreassociated proteins [55]. Although this adaptor protein, which connects and organises large fibrillar networks, has not previously been associated with breast cancer, upregulation of collagen XVI is associated with cell invasiveness and proliferation in glioblastoma and oral cancer [56, 57]. Moreover, the heparin-binding glycoprotein periostin, 

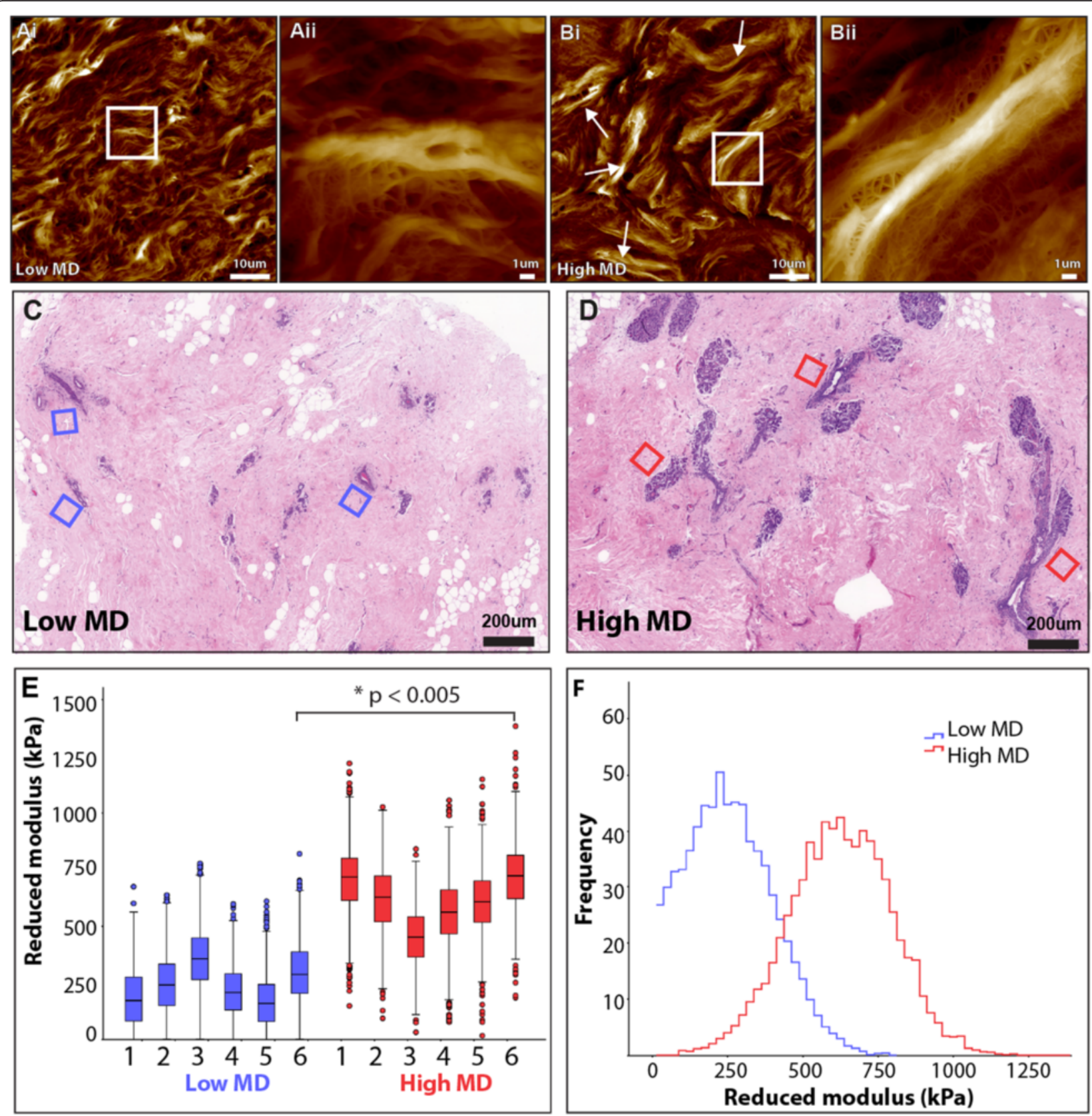

Fig. 5 Ultrastructure and micro-mechanical stiffness of peri-ductal tissue in patients with low and high mammographic density (MD). a, b Atomic force microscopy (AFM) height maps of tissue of low (a) and high (b) MD captured at $150 \times 150 \mu \mathrm{m}$ and a sampling frequency of $4992 \times 4992$. Arrows indicate collagen fibril bundles (fibres) in high MD breast tissue. aii, bii Magnified regions corresponding to the boxes in ai and bi. Low MD tissue, as depicted (ai and aii) was characterised by the presence of loose fibrillar collagen bundles. However (bi, bii), the central large fibrillar bundle is connected to surrounding tissue by a network of fine fibrils (150-450 nm diameter). c, d H\&E-stained breast biopsies from patients with low and high MD. Mechanical data were measured by atomic force microscopy (AFM) indentation $\left(20 \times 20\right.$ points) in $25-\mu m^{2}$ peri-ductal regions, shown in blue (low MD) and red (high MD) boxes. e, f Peri-ductal regions were significantly stiffer in patients with high MD compared with low $\mathrm{MD}(\mathrm{n}=12$ patients, $p<0.005)$

which is commonly found in tissues under high mechanical load, regulates collagen fibril morphology and potentially fibril crosslinking via BMP1- mediated activation of LOX $[50,52,58,59]$. Periostin is overexpressed in most breast cancers, where it enhances angiogenesis and tumour progression, and recruits Wnt ligands to maintain cancer stem cell maintenance $[60,61]$. Thus, proteomic analysis reveals that high MD is associated with the de novo expression of proteins that are involved with ECM remodelling and which might contribute to a cancerous phenotype. 


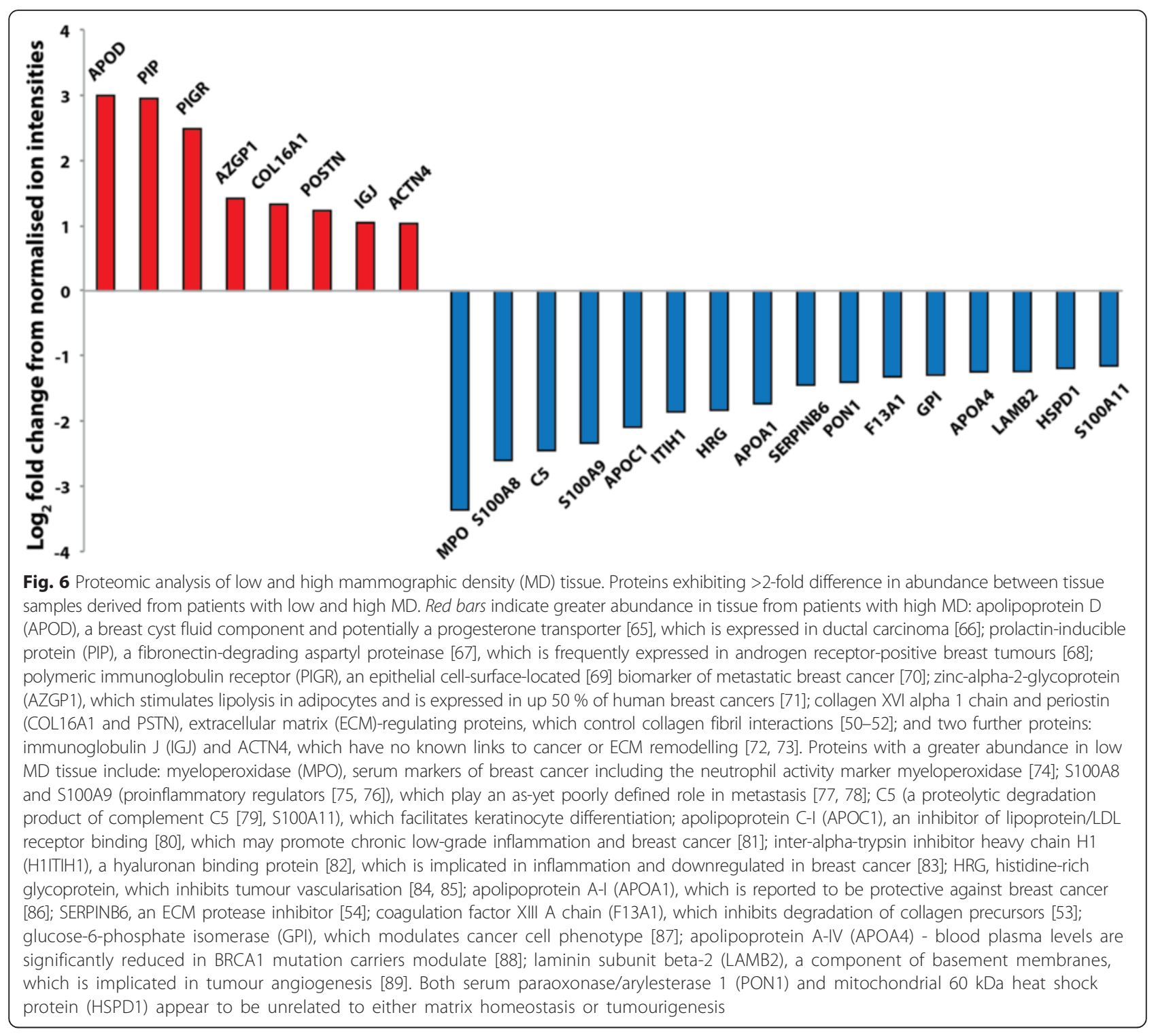

\section{Conclusions}

Here we provide initial data showing that, in a recently postmenopausal patient cohort, neither large-scale tissue remodelling between epithelial and stromal tissues, nor collagen deposition as assessed by both Masson's trichrome staining and mass spectrometry, correlates with MD. Instead, the peri-ductal regions of high MD breast tissue are characterized by: 1) the remodelling of collagen fibrils to form large collagen fibres, evident from both polarised light microscopy of PSR-stained sections and AFM, and 2) the upregulation of collagen-organising molecules, which have previously been identified as markers of breast cancer and metastatic colonisation rather than breast cancer risk [60, $62,63]$. Thus, the architectural remodelling of fibrillar collagens, rather than collagen fibrosis, may be a key molecular driver of raised MD, although other ECM remodelling events may also play a role. We suggest that this organisation of collagen fibrils into collagen fibres in turn increases the local mechanical stiffness of breast stroma. Although we do not yet know how collagen reorganisation into fibres in normal breast tissue may promote tumour initiation, organised collagen is a feature of human breast cancer. Indeed, collagen alignment within advanced cancer (e.g., the tumor-associated collagen signature-3 TACS-3 tissue architecture) is associated with disease outcome [104]. Given the limitations of the current study with regards to the relatively small size of the patient cohort, the inclusion of tissue from breasts that contain tumours and the highly localised nature of the mechanical mapping, further studies on the molecular causes of raised MD are clearly warranted.

Finally our data demonstrate that PSR, which is a commonly used collagen stain, is specific not for collagen fibrils, as was previously assumed, but for larger- 
scale organised collagen bundles. Given the impact of fibrotic diseases on human health, this ability to distinguish between structurally and functionally distinct forms of collagen has important implications for the interpretation of aberrant remodelling both in breast and in diverse fibrotic tissues [64].

\section{Additional files}

Additional file 1: Figure S1. Coherence of collagen organization in patients with low vs high mammographic density (MD). a, b Polarised Picrosirius red images $(\times 20)$ of peri-ductal stroma in an individual with low MD (a) and high MD (b). c, $\mathbf{d}$ Areas assessed by OrientationJ in individuals with low MD (c) and high MD (d). Colour coding is indicative of angle of collagen orientation. $\mathbf{d}$ Coherency values for six individuals with low vs six with high MD. (EPS $47751 \mathrm{~kb}$ )

Additional file 2: Table S1. Breast extracellular matrix (ECM) proteomic data. This table shows the ECM proteins detected in our mass spectrometry analysis of human breast tissue, plus those identified by mass spectrometry in rat mammary tumours, and the ECM of tumours resulting from the in vivo growth of the MD-MBA-231 breast cancer line. Green boxes indicate proteins that were identified in the analyses, red boxes show proteins not identified. The differences in expression may arise because completely different samples have been used, e.g., human vs rat, and normal human breast tissue vs a cancer line model. (DOC $124 \mathrm{~kb}$ )

Additional file 3: Table S2. Peptide frequencies for individual proteins identified in the mass spectrometry analysis. This table includes accession number, gene name and raw expression values for low and high mass spectrometry (MD) samples. (DOC $208 \mathrm{~kb}$ )

\section{Abbreviations}

AFM: atomic force microscopy; BRCA: breast cancer gene; CC: craniocaudal; ECM: extracellular matrix; ER: oestrogen receptor; HER-2: human epidermal growth factor receptor 2; MD: mammographic density; MLO: mediolateral oblique; PBS: phosphate-buffered saline; PSR: Picrosirius red; VAS: visual analogue score.

\section{Competing interests}

The authors declare that they have no competing interests.

\section{Authors' contributions}

CHS and MJS conceived and designed the study. MJS, CHS, AG and JCM developed key data collection methodologies. JCM performed the histology, microscopy and AFM data collection and analysis. OVO performed the proteomics data collection assisted by $\mathrm{RO}^{\prime} \mathrm{C}$ and was supervised in the mass spectrometry analysis by DK. KB contributed to the design of the study and interpretation of collected data. LW performed the experiments that started the study, and that enabled the grant applications to be written that allowed the study to be finished. MH was the surgical pathologist who provided the material for the study. $\sqcup$ was the histopathologist who provided histology reads for the study. YL was the radiologist that performed mammographic analysis for the study. AL and RW consented the patients, collected anthropometric data, and obtained all the human material that was used for the study. JR supervised patient recruitment and obtained all the human material that was used for the study, also providing ethical permissions, medical data and sample storage. SMA provided all the density data analysis reported. AG and CCK provided the patient tissue for the study and were intellectual contributors to the conception and design of the reported work throughout. Analysis and interpretation of the data was conducted by JCM, OVO, MJS, CHS, SMA, AG, CCK and KB. The manuscript was written by JCM, MJS, CHS, AG, SMA, CCK, DK and KB. All named authors have been involved in drafting and revising the manuscript, have given final approval of the version to be published and agree to be accountable for all aspects of accuracy or integrity in relation to this study.

\section{Acknowledgements}

The authors wish to gratefully acknowledge funding from Genesis Breast Cancer Prevention (grant R116883 awarded to CHS and MJS), the Medical Research Council UK (grant G1001398 awarded to MJS), and to an ISSF Biomedical Research Consortia Award (awarded to CHS, MJS, AG, JR, SA, and KB) and the Wellcome Trust (097820/Z/11/A). We are also grateful to Dr Nigel Hodson of the University of Manchester BioAFM Facility for his advice on AFM imaging and force spectroscopy. This was a joint study by the Sherratt laboratory and the Streuli laboratory.

\section{Author details}

${ }^{1}$ Centre for Tissue Injury \& Repair, Faculty of Medical and Human Sciences, University of Manchester, Manchester, UK. ${ }^{2}$ Wellcome Trust Centre for Cell-Matrix Research and Manchester Breast Centre, Faculty of Life Sciences, University of Manchester, Manchester, UK. ${ }^{3}$ University Hospital of South Manchester, Manchester, UK. ${ }^{4}$ Centre for Imaging Sciences, Institute of Population Health, Faculty of Medical and Human Sciences, University of Manchester, Manchester, UK. ${ }^{5}$ Institute of Cancer Sciences, Manchester Academic Health Sciences Centre, University Hospital of South Manchester, University of Manchester, Manchester, UK. ${ }^{6}$ Manchester Cancer Research Centre Tissue Biobank, University of Manchester, Manchester, UK.

Received: 25 September 2015 Accepted: 15 December 2015 Published online: 08 January 2016

\section{References}

1. Boyd NF, Martin LJ, Bronskill M, Yaffe MJ, Duric N, Minkin S. Breast tissue composition and susceptibility to breast cancer. J Natl Cancer Inst. 2010; 102(16):1224-37. doi:10.1093/jnci/djq239.

2. McCormack VA. Breast density and parenchymal patterns as markers of breast cancer risk: a meta-analysis. Cancer Epidemiol Biomark Prev. 2006; 15(6):1159-69. doi:10.1158/1055-9965.epi-06-0034.

3. Boyd NF, Martin LJ, Yaffe MJ, Minkin S. Mammographic density and breast cancer risk: current understanding and future prospects. Breast Cancer Res. 2011;13(6):223. doi:10.1186/bcr2942.

4. Vachon CM, van Gils CH, Sellers TA, Ghosh K, Pruthi S, Brandt KR, et al. Mammographic density, breast cancer risk and risk prediction. Breast Cancer Res. 2007;9(6):217. doi:10.1186/bcr1829.

5. Cuzick J, Warwick J, Pinney E, Duffy SW, Cawthorn S, Howell A, et al. Tamoxifen-induced reduction in mammographic density and breast cancer risk reduction: a nested case-control study. J Natl Cancer Inst. 2011;103(9): 744-52. doi:10.1093/jnci/djr079.

6. Henry NL, Chan HP, Dantzer J, Goswami CP, Li L, Skaar TC, et al. Aromatase inhibitor-induced modulation of breast density: clinical and genetic effects. Br J Cancer. 2013;109(9):2331-9. doi:10.1038/bjc.2013.587.

7. Slanetz PJ, Freer PE, Birdwell RL. Breast-density legislation — practical considerations. N Engl J Med. 2015;372(7):593-5. doi:10.1056/nejmp1413728.

8. Ghosh K, Brandt KR, Reynolds C, Scott CG, Pankratz VS, Riehle DL, et al. Tissue composition of mammographically dense and non-dense breast tissue. Breast Cancer Res Treat. 2011;131(1):267-75. doi:10.1007/s10549-011$1727-4$.

9. Lee NA, Rusinek $\mathrm{H}$, Weinreb J, Chandra R, Toth $\mathrm{H}$, Singer $\mathrm{C}$, et al. Fatty and fibroglandular tissue volumes in the breasts of women 20-83 years old: comparison of X-ray mammography and computer-assisted MR imaging. Am J Roentgenol. 1997;168(2):501-6. doi:10.2214/ajr.168.2.9016235.

10. Alowami S, Troup S, Al-Haddad S, Kirkpatrick I, Watson PH. Mammographic density is related to stroma and stromal proteoglycan expression. Breast Cancer Res. 2003;5(5):R129. doi:10.1186/bcr622.

11. Lin SJ, Cawson J, Hill P, Haviv I, Jenkins M, Hopper JL, et al. Image-guided sampling reveals increased stroma and lower glandular complexity in mammographically dense breast tissue. Breast Cancer Res Treat. 2011;128(2):505-16. doi:10.1007/s10549-011-1346-0.

12. Muschler J, Streuli CH. Cell-matrix interactions in mammary gland development and breast cancer. Cold Spring Harb Perspect Biol. 2010;2(10): a003202-a. doi:10.1101/cshperspect.a003202.

13. Provenzano PP, Inman DR, Eliceiri KW, Knittel JG, Yan L, Rueden CT, et al. Collagen density promotes mammary tumor initiation and progression. BMC Med. 2008;6(1):11. doi:10.1186/1741-7015-6-11.

14. Bancroft JD, Gamble M. Theory and practice of histological techniques. Edinburgh, UK: Elsevier Health Sciences; 2008. 
15. Gnerlich JL, Yao KA, Fitchev PS, Goldschmidt RA, Bond MC, Cornwell M, et al. Peritumoral expression of adipokines and fatty acids in breast cancer. Ann Surg Oncol. 2013;20(S3):731-8. doi:10.1245/s10434-013-3274-1.

16. Pandya HJ, Chen W, Goodell LA, Foran DJ, Desai JP. Mechanical phenotyping of breast cancer using MEMS: a method to demarcate benign and cancerous breast tissues. Lab Chip. 2014;14(23):4523-32. doi:10.1039/c4lc00594e.

17. Sadanandam A, Lal A, Benz SC, Eppenberger-Castori S, Scott G, Gray JW, et al. Genomic aberrations in normal tissue adjacent to HER2amplified breast cancers: field cancerization or contaminating tumor cells? Breast Cancer Res Treat. 2012;136(3):693-703. doi:10.1007/s10549012-2290-3.

18. Schnabel F, Boolbol SK, Gittleman M, Karni T, Tafra L, Feldman S, et al. A randomized prospective study of lumpectomy margin assessment with Use of MarginProbe in patients with nonpalpable breast malignancies. Ann Surg Oncol. 2014;21(5):1589-95. doi:10.1245/s10434-014-3602-0.

19. Highnam R, Brady M, Yaffe MJ, Karssemeijer N, Harvey J. Robust breast composition measurement- Volpara(TM). In: Digital Mammography. Germany: Springer Berlin Heidelberg; 2010. p. 342-9.doi:10.1186/s13058-015-0664-2

20. Ekpo EU, McEntee MF. Measurement of breast density with digital breast tomosynthesis_a systematic review. Br J Radiol. 2014;87(1043):20140460. doi:10.1259/bjr.20140460.

21. Boyd NF, Lockwood GA, Byng JW, Little LE, Yaffe MJ, Tritchler DL. The relationship of anthropometric measures to radiological features of the breast in premenopausal women. Br J Cancer. 1998;78(9):1233-8. doi:10.1038/bjc.1998.660.

22. Kim YT, Park JC, Choi SH, Cho KS, Im Gl, Kim BS, et al. The dynamic healing profile of human periodontal ligament stem cells: histological and immunohistochemical analysis using an ectopic transplantation model. J Periodontal Res. 2012;47(4):514-24. doi:10.1111/j.1600-0765.2011.01463.x.

23. Abraham BK, Fritz P, McClellan M, Hauptvogel P, Athelogou M, Brauch $H$. Prevalence of CD44+/CD24-/low cells in breast cancer may not be associated with clinical outcome but may favor distant metastasis. Clin Cancer Res. 2005;11(3):1154-9.

24. Akhtar R, Sherratt MJ, Cruickshank JK, Derby B. Characterizing the elastic properties of tissues. Mater Today. 2011;14(3):96-105. doi:10.1016/s13697021(11)70059-1.

25. Junqueira LCU, Bignolas G, Brentani RR. Picrosirius staining plus polarization microscopy, a specific method for collagen detection in tissue sections. Histochem J. 1979;11(4):447-55. doi:10.1007/bf01002772.

26. Graham HK, Akhtar R, Kridiotis C, Derby B, Kundu T, Trafford AW, et al. Localised micro-mechanical stiffening in the ageing aorta. Mech Ageing Dev. 2011;132(10):459-67. doi:10.1016/j.mad.2011.07.003.

27. Graham HK, Trafford AW. Spatial disruption and enhanced degradation of collagen with the transition from compensated ventricular hypertrophy to symptomatic congestive heart failure. Am J Physiol Heart Circ Physiol. 2006; 292(3):H1364-H72. doi:10.1152/ajpheart.00355.2006.

28. Bauman TM, Nicholson TM, Abler LL, Eliceiri KW, Huang W, Vezina CM, et al. Characterization of fibrillar collagens and extracellular matrix of glandular benign prostatic hyperplasia nodules. PLoS ONE. 2014;9(10):e109102. doi:10. 1371/journal.pone.0109102.

29. Salchert K, Streller U, Pompe T, Herold N, Grimmer M, Werner C. In vitro reconstitution of fibrillar collagen type I assemblies at reactive polymer surfaces. Biomacromolecules. 2004;5(4):1340-50. doi:10.1021/bm0499031.

30. Graham HK, Hodson NW, Hoyland JA, Millward-Sadler SJ, Garrod D, Scothern A, et al. Tissue section AFM: in situ Ultrastructural imaging of native biomolecules. Matrix Biol. 2010;29(4):254-60. doi:10.1016/j.matbio. 2010.01.008

31. Crick SL, Yin FCP. Assessing micromechanical properties of cells with atomic force microscopy: importance of the contact point. Biomech Model Mechanobiol. 2006;6(3):199-210. doi:10.1007/s10237-006-0046-x

32. Ngoka LCM. Sample prep for proteomics of breast cancer: proteomics and gene ontology reveal dramatic differences in protein solubilization preferences of radioimmunoprecipitation assay and urea lysis buffers. Proteome Sci. 2008;6(1):30. doi:10.1186/1477-5956-6-30

33. Wiśniewski JR, Zougman A, Nagaraj N, Mann M. Universal sample preparation method for proteome analysis. Nat Methods. 2009;6(5):359-62. doi:10.1038/nmeth.1322.

34. Vlasblom J, Wodak SJ. Markov clustering versus affinity propagation for the partitioning of protein interaction graphs. BMC Bioinformatics. 2009;10(1):99. doi:10.1186/1471-2105-10-99.
35. Gubern-Mérida A, Kallenberg M, Platel B, Mann RM, Martí R, Karssemeijer N. Volumetric breast density estimation from full-field digital mammograms: a validation study. PLoS ONE. 2014;9(1):e85952. doi:10.1371/journal.pone. 0085952.

36. Wang J, Azziz A, Fan B, Malkov S, Klifa C, Newitt D, et al. Agreement of mammographic measures of volumetric breast density to MRI. PLOS ONE. 2013;8(12):e81653. doi:10.1371/journal.pone.0081653.

37. Li T. The association of measured breast tissue characteristics with mammographic density and other risk factors for breast cancer. Cancer Epidemiol Biomark Prev. 2005;14(2):343-9. doi:10.1158/1055-9965.epi-04-0490.

38. Wei SC, Fattet L, Tsai JH, Guo Y, Pai VH, Majeski HE, et al. Matrix stiffness drives epithelial-mesenchymal transition and tumour metastasis through a TWIST1-G3BP2 mechanotransduction pathway. Nat Cell Biol. 2015;17(5):678-88. doi:10.1038/ncb3157.

39. Kemp AD, Harding CC, Cabral WA, Marini JC, Wallace JM. Effects of tissue hydration on nanoscale structural morphology and mechanics of individual Type I collagen fibrils in the Brtl mouse model of Osteogenesis Imperfecta. J Struct Biol. 2012;180(3):428-38. doi:10.1016/j.jsb.2012.09.012.

40. Wallace JM, Harding C, Kemp A. Effects of Hydration on Nanoscale Structural Morphology and Mechanics of Individual Type I Collagen Fibrils. MRS Proc. 2012;1465. doi:10.1557/opl.2012.926

41. Barcus CE, Keely PJ, Eliceiri KW, Schuler LA. Stiff collagen matrices increase tumorigenic prolactin signaling in breast cancer cells. J Biol Chem. 2013;288(18):12722-32. doi:10.1074/jbc.m112.447631.

42. Birk DE, Brückner P. Collagens, suprastructures, and collagen fibril assembly. The Extracellular Matrix: an Overview. Germany: Springer Berlin Heidelberg; 2011. p. 77-115.

43. Kass L, Erler JT, Dembo M, Weaver VM. Mammary epithelial cell: Influence of extracellular matrix composition and organization during development and tumorigenesis. Int J Biochem Cell Biol. 2007;39(11):1987-94. doi:10.1016/j. biocel.2007.06.025.

44. Provenzano PP, Vanderby R. Collagen fibril morphology and organization: Implications for force transmission in ligament and tendon. Matrix Biol. 2006;25(2):71-84. doi:10.1016/..matbio.2005.09.005.

45. Baldwin Samuel J, Quigley Andrew S, Clegg C, Kreplak L. Nanomechanical mapping of hydrated Rat tail tendon collagen I fibrils. Biophys J. 2014;107(8):1794-801. doi:10.1016/j.bpj.2014.09.003.

46. Fischer-Cripps AC. A review of analysis methods for sub-micron indentation testing. Vacuum. 2000;58(4):569-85. doi:10.1016/50042-207x(00)00377-8.

47. Franke K, Sapudom J, Kalbitzer L, Anderegg U, Pompe T. Topologically defined composites of collagen types I and $\mathrm{V}$ as in vitro cell culture scaffolds. Acta Biomater. 2014;10(6):2693-702. doi:10.1016/j.actbio.2014.02.036.

48. Zhang G, Ezura Y, Chervoneva I, Robinson PS, Beason DP, Carine ET, et al. Decorin regulates assembly of collagen fibrils and acquisition of biomechanical properties during tendon development. J Cell Biochem. 2006;98(6):1436-49. doi:10.1002/jcb.20776.

49. Kadler KE, Hill A, Canty-Laird EG. Collagen fibrillogenesis: fibronectin, integrins, and minor collagens as organizers and nucleators. Curr Opin Cell Biol. 2008;20(5):495-501. doi:10.1016/j.ceb.2008.06.008.

50. Egbert M, Ruetze M, Sattler M, Wenck H, Gallinat S, Lucius R, et al. The matricellular protein periostin contributes to proper collagen function and is downregulated during skin aging. J Dermatol Sci. 2014;73(1):40-8. doi:10.1016/j.jdermsci.2013.08.010

51. Grässel S, Bauer RJ. Collagen XVI in health and disease. Matrix Biol. 2013;32(2):64-73. doi:10.1016/j.matbio.2012.11.001.

52. Tabata C, Hongo H, Sasaki M, Hasegawa T, de Freitas PH, Yamada T, et al. Altered distribution of extracellular matrix proteins in the periodontal ligament of periostin-deficient mice. Histol Histopathol. 2014;29(6):731-42.

53. Paye M, Nusgens B, Lapière CM. Factor XIII of blood coagulation decreases the susceptibility of collagen precursors to proteolysis. Biochim Biophys Acta Gen Subj. 1991;1073(3):437-41. doi:10.1016/0304-4165(91)90212-y.

54. Scott FL, Hirst CE, Sun J, Bird CH, Bottomley SP, Bird PI. The intracellular serpin proteinase inhibitor 6 is expressed in monocytes and granulocytes and is a potent inhibitor of the azurophilic granule protease, cathepsin $\mathrm{G}$. Blood. 1999:93(6):2089-97.

55. Eble JA, Kassner A, Niland S, Morgelin M, Grifka J, Grassel S. Collagen XVI harbors an integrin 1 beta1 recognition site in its C-terminal domains. J Biol Chem. 2006;281(35):25745-56. doi:10.1074/jbc.m509942200.

56. Bauer R, Ratzinger S, Wales L, Bosserhoff A, Senner V, Grifka J, et al. Inhibition of collagen XVI expression reduces glioma cell invasiveness. Cell Physiol Biochem. 2011;27(3-4):217-26. doi:10.1159/000327947. 
57. Ratzinger S, Grässel S, Dowejko A, Reichert TE, Bauer RJ. Induction of type $\mathrm{XVI}$ collagen expression facilitates proliferation of oral cancer cells. Matrix Biol. 2011;30(2):118-25. doi:10.1016/j.matbio.2011.01.001.

58. Maruhashi T, Kii I, Saito M, Kudo A. Interaction between Periostin and BMP-1 Promotes Proteolytic Activation of Lysyl Oxidase. J Biol Chem. 2010;285(17):13294-303. doi:10.1074/jbc.m109.088864

59. Norris RA, Damon B, Mironov V, Kasyanov V, Ramamurthi A, MorenoRodriguez $R$, et al. Periostin regulates collagen fibrillogenesis and the biomechanical properties of connective tissues. J Cell Biochem. 2007;101(3):695-711. doi:10.1002/jcb.21224.

60. Malanchi I, Santamaria-Martínez A, Susanto E, Peng H, Lehr H-A, Delaloye J-F, et al. Interactions between cancer stem cells and their niche govern metastatic colonization. Nature. 2011;481(7379):85-9. doi:10.1038/nature10694.

61. Shao R, Bao S, Bai X, Blanchette C, Anderson RM, Dang T, et al. Acquired expression of periostin by human breast cancers promotes tumor angiogenesis through Up-regulation of vascular endothelial growth factor receptor 2 expression. Mol Cell Biol. 2004;24(9):3992-4003. doi:10.1128/mcb.24.9.3992-4003.2004.

62. Wang Z, Ouyang G. Periostin: a bridge between cancer stem cells and their metastatic niche. Cell Stem Cell. 2012;10(2):111-2. doi:10.1016/j. stem.2012.01.002

63. Xu D, Xu H, Ren Y, Liu C, Wang X, Zhang H, et al. Cancer stem cell-related gene periostin: a novel prognostic marker for breast cancer. PLoS ONE. 2012;7(10):e46670. doi:10.1371/journal.pone.0046670.

64. Wynn TA. Cellular and molecular mechanisms of fibrosis. J Pathol. 2008;214(2):199-210. doi:10.1002/path.2277.

65. Balbin M, Freije JM, Fueyo A, Sanchez LM, Lopez-Otin C. Apolipoprotein D is the major protein component in cyst fluid from women with human breast gross cystic disease. Biochem J. 1990;271(3):803-7.

66. Gonzalez LO, Corte MD, Junquera S, Bongera M, Rodriguez JC, Vizoso FJ. Expression of androgen receptor and two androgen-induced proteins (apolinf poprotein D and pepsinogen C) in ductal carcinoma in situ of the breast. Histopathology. 2007;50(7):866-74. doi:10.1111/j.1365-2559. 2007.02687.x.

67. Caputo E. A novel aspartyl proteinase from apocrine epithelia and breast tumors. J Biol Chem. 2000;275(11):7935-41. doi:10.1074/jbc.275.11.7935.

68. Darb-Esfahani S, von Minckwitz G, Denkert C, Ataseven B, Högel B, Mehta K, et al. Gross cystic disease fluid protein 15 (GCDFP-15) expression in breast cancer subtypes. BMC Cancer. 2014;14(1):546. doi:10.1186/1471-2407-14-546.

69. Hamburger AE, West AP, Bjorkman PJ. Crystal structure of a polymeric immunoglobulin binding fragment of the human polymeric immunoglobulin receptor. Structure. 2004;12(11):1925-35. doi:10.1016/j.str.2004.09.006.

70. Fry SA, Sinclair J, Timms JF, Leathem AJ, Dwek MV. A targeted glycoproteomic approach identifies cadherin-5 as a novel biomarker of metastatic breast cancer. Cancer Lett. 2013;328(2):335-44. doi:10.1016/j. canlet.2012.10.011.

71. Hale LP, Price DT, Sanchez LM, Demark-Wahnefried W, Madden JF. Zinc alpha-2-glycoprotein is expressed by malignant prostatic epithelium and may serve as a potential serum marker for prostate cancer. Clin Cancer Res. 2001;7(4):846-53.

72. Braathen R, Hohman VS, Brandtzaeg P, Johansen FE. Secretory antibody formation: conserved binding interactions between J chain and polymeric Ig receptor from humans and amphibians. J Immunol. 2007;178(3):1589-97. doi:10.4049/jimmunol.178.3.1589.

73. Gerhard D. The status, quality, and expansion of the NIH full-length cDNA project: the mammalian gene collection (MGC). Genome Res. 2004;14(10b):2121-7. doi:10.1101/gr.2596504.

74. Coelho BA, Belo AV, Andrade SP, Amorim WC, Uemura G, da Silva Filho AL. $\mathrm{N}$-acetylglucosaminidase, myeloperoxidase and vascular endothelial growth factor serum levels in breast cancer patients. Biomed Pharmacother. 2014;68(2):185-9. doi:10.1016/j.biopha.2013.10.009.

75. Koike A, Arai S, Yamada S, Nagae A, Saita N, Itoh H, et al. Dynamic mobility of immunological cells expressing S100A8 and S100A9 in vivo: a variety of functional roles of the two proteins as regulators in acute inflammatory reaction. Inflammation. 2011;35(2):409-19. doi:10.1007/s10753-011-9330-8.

76. Ryckman C, Vandal K, Rouleau P, Talbot M, Tessier PA. Proinflammatory activities of S100: proteins S100A8, S100A9, and S100A8/A9 induce neutrophil chemotaxis and adhesion. J Immunol. 2003;170(6):3233-42. doi:10.4049/jimmunol.170.6.3233.

77. Drews-Elger K, lorns E, Dias A, Miller P, Ward TM, Dean S, et al. Infiltrating S100A8+ myeloid cells promote metastatic spread of human breast cancer and predict poor clinical outcome. Breast Cancer Res Treat. 2014;148(1):41-59. doi:10.1007/s10549-014-3122-4.

78. Ehrchen JM, Sunderkotter C, Foell D, Vogl T, Roth J. The endogenous Tolllike receptor 4 agonist S100A8/S100A9 (calprotectin) as innate amplifier of infection, autoimmunity, and cancer. J Leukoc Biol. 2009;86(3):557-66. doi:10.1189/jlb.1008647.

79. Monk PN, Scola AM, Madala P, Fairlie DP. Function, structure and therapeutic potential of complement C5a receptors. Br J Pharmacol. 2007;152(4):429-48. doi:10.1038/sj.bjp.0707332.

80. Westerterp M, Berbee JFP, Delsing DJM, Jong MC, Gijbels MJJ, Dahlmans VEH, et al. Apolipoprotein C-I binds free fatty acids and reduces their intracellular esterification. J Lipid Res. 2007;48(6):1353-61. doi:10.1194/jlr. m700024-jlr200.

81. Prizment AE, Folsom AR, Dreyfus J, Anderson KE, Visvanathan K, Joshu CE, et al. Plasma C-reactive protein, genetic risk score, and risk of common cancers in the Atherosclerosis Risk in Communities study. Cancer Causes Control. 2013;24(12):2077-87. doi:10.1007/s10552-013-0285-y.

82. Zhao M, Yoneda M, Ohashi Y, Kurono S, Iwata H, Ohnuki Y, et al. Evidence for the covalent binding of SHAP, heavy chains of inter- -trypsin inhibitor, to hyaluronan. J Biol Chem. 1995;270(44):26657-63. doi:10.1074/jbc. 270.44.26657.

83. Hamm A, Veeck J, Bektas N, Wild PJ, Hartmann A, Heindrichs U, et al. Frequent expression loss of Inter-alpha-trypsin inhibitor heavy chain $(\mathrm{ITIH})$ genes in multiple human solid tumors: A systematic expression analysis. BMC Cancer. 2008;8(1):25. doi:10.1186/1471-2407-8-25.

84. Olsson AK. A fragment of histidine-rich glycoprotein is a potent inhibitor of tumor vascularization. Cancer Res. 2004;64(2):599-605. doi:10.1158/0008-5472.can-03-1941.

85. Schaub NP, Jones KJ, Nyalwidhe JO, Cazares LH, Karbassi ID, Semmes OJ, et al. Serum proteomic biomarker discovery reflective of stage and obesity in breast cancer patients. J Am Coll Surg. 2009;208(5):970-8. doi:10.1016/j. jamcollsurg.2008.12.024.

86. His M, Zelek L, Deschasaux M, Pouchieu C, Kesse-Guyot E, Hercberg S, et al. Prospective associations between serum biomarkers of lipid metabolism and overall, breast and prostate cancer risk. Eur J Epidemiol. 2014;29(2):1 19-32. doi:10.1007/s10654-014-9884-5.

87. Ahmad A, Aboukameel A, Kong D, Wang Z, Sethi S, Chen W, et al. Phosphoglucose isomerase/autocrine motility factor mediates epithelialmesenchymal transition regulated by miR-200 in breast cancer cells. Cancer Res. 2011;71(9):3400-9. doi:10.1158/0008-5472.can-10-0965.

88. Custodio A, López-Farré AJ, Zamorano-León JJ, Mateos-Cáceres PJ, Macaya C, Caldés T, et al. Changes in the expression of plasma proteins associated with thrombosis in BRCA1 mutation carriers. J Cancer Res Clin Oncol. 2012;138(5):867-75. doi:10.1007/s00432-012-1161-y.

89. Kalluri R. Angiogenesis: Basement membranes: structure, assembly and role in tumour angiogenesis. Nat Rev Cancer. 2003;3(6):422-33. doi:10.1038/nrc1094.

90. Sweers KK, Van Der Werf KO, Bennink ML, Subramaniam V. Spatially resolved frequency-dependent elasticity measured with pulsed force microscopy and nanoindentation. Nanoscale. 2012;4:2072-7.

91. Young TJ, Monclus MA, Burnett TL, Broughton WR, Ogin SL, Smith PA. The use of the PeakForceTM quantitative nanomechanical mapping AFM-based method for high-resolution Young's modulus measurement of polymers. Meas Sci Technol. 2011;22(12):125703.

92. Acerbi IR, Cassereau L, Dean I, Shi Q, Au A, Park C, et aL. Human breast cancer invasion and aggression correlates with ECM stiffening and immune cell infiltration. Integrative Biol. 2015;7:1120-34.

93. Plodinec M, Loparic M, Monnier CA, Obermann EC, Zanetti-Dallenbach R, Oertle $P$, et al. The nanomechanical signature of breast cancer. Nat Nanotechnol. 2012;7(11):757-65.

94. Mackay JL, Kumar S. Measuring the elastic properties of living cells with atomic force microscopy indentation. In: Cell Imaging Techniques. New York City, NY, USA: Humana Press; 2015. p. 313-29.

95. McKee CT, Last JA, Russell P, Murphy CJ. Indentation versus tensile measurements of Young's modulus for soft biological tissues. Tissue Eng $B$ Rev. 2011;17(3):155-64.

96. Dias J, Ziebarth NM. Viscoelastic characterization of the corneal stroma assessed Ex vivo using atomic force microscopy. Invest Ophthalmol Vis Sci. 2014;55(13):3708-8.

97. Chang YR, Raghunathan VK, Garland SP, Morgan JT, Russell P, Murphy CJ. Automated AFM force curve analysis for determining elastic modulus of 
biomaterials and biological samples. J Mech Behav Biomed Mater. 2014;37:209-18.

98. Baldwin SJ, Quigley AS, Clegg C, Kreplak L. Nanomechanical mapping of hydrated Rat tail tendon collagen I fibrils. Biophys J. 2014;107(8):1794-801.

99. Grant CA, Twigg PC, Tobin DJ. Static and dynamic nanomechanical properties of human skin tissue using atomic force microscopy: effect of scarring in the upper dermis. Acta Biomater. 2012;8(11):4123-9.

100. Bredfeldt JS, Liu Y, Conklin MW, Keely PJ, Mackie TR, Eliceiri KW. Automated quantification of aligned collagen for human breast carcinoma prognosis. J Pathol Inform. 2014;5:28. doi:10.4103/2153-3539.139707.eCollection2014.

101. Hansen KC, Kiemele L, Maller O, O'Brien J, Shankar A, Fornetti J, et al. An insolution ultrasonication-assisted digestion method for improved extracellular matrix proteome coverage. Mol Cell Proteomics. 2009;8(7):1648-57. doi:10.1074/mcp.M900039-MCP200. Epub 2009 Apr 7.

102. O'Brien JH, Vanderlinden LA, Schedin PJ, Hansen KC. Rat mammary extracellular matrix composition and response to ibuprofen treatment during postpartum involution by differential GeLC-MS/MS analysis. J Proteome Res. 2012;11(10):4894-905. doi:10.1021/pr3003744. Epub 2012 Aug 30.

103. Naba A, Clauser KR, Lamar JM, Carr SA, Hynes RO. Extracellular matrix signatures of human mammary carcinoma identify novel metastasis promoters. Elife. 2014;3:e01308. doi:10.7554/eLife.01308.

104. Conklin MW, Eickhoff JC, Riching KM, Pehlke CA, Eliceiri KW, Provenzano PP, et al. Aligned collagen is a prognostic signature for survival in human breast carcinoma. Am J Pathol. 2011;178(3):1221-32. doi:10.1016/j.ajpath. 2010.11.076.

105. Rezakhaniha R, Agianniotis A, Schrauwen JT, Griffa A, Sage D, Bouten CV, et al. Experimental investigation of collagen waviness and orientation in the arterial adventitia using confocal laser scanning microscopy. Biomech Model Mechanobiol. 2012;11(3-4):461-73. doi:10.1007/s10237-011-0325-z. Epub 2011 Jul 10.

106. Naba A, Clauser KR, Hoersch S, Liu H, Carr SA, Hynes RO. The matrisome: in silico definition and in vivo characterization by proteomics of normal and tumor extracellular matrices. Mol Cell Proteomics. 2011;11:mcp-M111.

\section{Submit your next manuscript to BioMed Central and we will help you at every step:}

- We accept pre-submission inquiries

- Our selector tool helps you to find the most relevant journal

- We provide round the clock customer support

- Convenient online submission

- Thorough peer review

- Inclusion in PubMed and all major indexing services

- Maximum visibility for your research

Submit your manuscript at www.biomedcentral.com/submit

C Biomed Central 